\title{
Greening monetary policy
}

\author{
Dirk Schoenmaker
}

To cite this article: Dirk Schoenmaker (2021): Greening monetary policy, Climate Policy, DOI: 10.1080/14693062.2020.1868392

To link to this article: https://doi.org/10.1080/14693062.2020.1868392

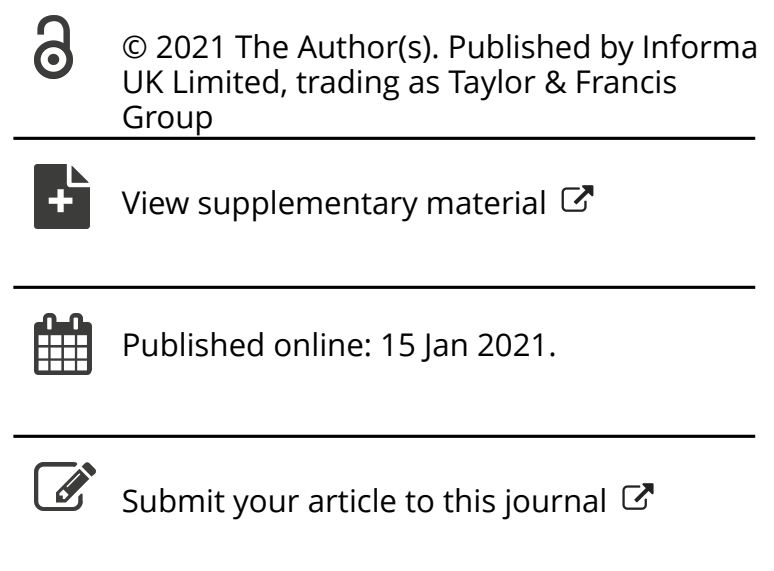

Џلll Article views: 555

Q View related articles

View Crossmark data $\nearrow$ 


\title{
Greening monetary policy
}

\author{
Dirk Schoenmaker
}

Rotterdam School of Management, Erasmus University, Rotterdam, Netherlands

\begin{abstract}
While there is increasing interest in decarbonizing or greening monetary policy, central banks are keen to maintain market neutrality. However, there is evidence that the market has a bias towards carbon-intensive companies. The paper develops a method to tilt the European Central Bank's (ECB) asset and collateral framework towards low-carbon assets. We find that a medium tilting approach reduces carbon emissions in the ECB's corporate and bank bond portfolio by over $50 \%$. We show that a low carbon allocation can be done without undue interference with the transmission mechanism of monetary policy.
\end{abstract}

\section{Key policy insights:}

- The ECB's asset and collateral portfolio for monetary policy operations is overweight in high carbon companies.

- A medium tilting approach towards low-carbon companies reduces carbon emissions by $55 \%$ in the ECB's portfolio.

- It also reduces the cost of capital for low carbon companies. This is an incentive for high carbon companies to reform and adopt low carbon technologies.
ARTICLE HISTORY

Received 24 July 2020

Accepted 18 December 2020

\section{KEYWORDS}

Monetary policy; collateral; decarbonizing; carbon emissions; cost of capital

\section{Introduction}

Climate change has an impact on the economy and the underlying financial system in the medium to long term (Stern, 2008). In their pursuit of price and financial stability, central banks also adopt a medium to long term view on economic and financial developments. In their second role of ensuring financial stability, central banks have started to examine the impact of climate-related risks on the stability of the financial system (Battiston et al., 2017; Campiglio et al., 2018; Carney, 2015; Reinders et al., 2020). The Financial Stability Board's Task Force on Climate-related Financial Disclosures (TCFD, 2017) has developed consistent climate-related financial disclosures for financial reporting by companies and financial institutions.

By contrast, in their first role of monetary policy, central banks have a long-standing policy of market neutrality. However, there is evidence that the market has a bias towards carbon-intensive companies (Matikainen et al., 2017). As carbon-intensive companies, like oil and gas companies and car manufacturers, are typically also capital intensive (Doda, 2016), market indices for corporate bonds are overweight in high-carbon companies. By taking assets proportional to the market index, central banks are thus not climate neutral in their implementation of monetary policy. The monetary transmission mechanism is the process by which asset prices and general economic conditions are affected by monetary policy decisions (Aksoy \& Basso, 2014). By favouring high-carbon corporate bonds, central banks improve the liquidity of these bonds, thereby lowering the cost of capital for high-carbon companies in comparison with low-carbon ones. This improves the competitive position of high-carbon companies, resulting in higher overall carbon emissions. 
In the case of the European Central Bank (ECB), the market neutral approach undermines the general economic policy of the EU to achieve a low-carbon economy (European Commission, 2019). This raises the question of what the role of the ECB is regarding the EU's general economic policies. The Treaty on the Functioning of the European Union (Article 127) specifies price stability as the primary objective and supporting general economic policies in the Union as a secondary objective of the ECB. The Treaty on European Union (Article 3) adopts a broad definition of economic policies, which include policies that affect society and the environment (see, for example, Stiglitz Report, 2009). The legal mandate derived from the EU Treaties thus provides scope for the ECB to support the transition to a low-carbon economy, without prejudice to price stability.

The research question in this paper is how the ECB can decarbonize or green its monetary policy operations. These operations involve allocation decisions when purchasing assets and taking collateral. The ECB has developed 'eligibility criteria' for which type of assets are eligible for purchase or collateral purposes (Nyborg, 2017). Any greening of monetary policy operations should follow a general approach, avoiding sector specific allocations (Smits, 1997). Another condition is that the transmission mechanism of monetary policy should not be unduly affected (Aksoy \& Basso, 2014). A green allocation policy must be designed and executed so that it does not interfere with the effective implementation of monetary policy.

The contribution of this paper is twofold. First, we develop a novel method to green monetary policy operations by steering or tilting the allocation of assets and collateral from high-carbon companies towards lowcarbon companies in a general way. This lowers the cost of capital for the low-carbon companies in comparison to high-carbon ones.

Next, we investigate which parts of the ECB's asset and collateral base are affected by our mechanism to green monetary policy. We also provide some numerical examples based on European corporate and bank bonds. We find that a tilting approach can counter the carbon bias and reduce carbon emissions in the corporate and bank bond portfolio by $55 \%$.

The paper is organized as follows. Section 2 develops a methodology to green monetary policy. Next, Section 3 analyses the effects of greening monetary policy. Finally, Section 4 concludes with a policy discussion.

\section{Towards a method for greening monetary policy}

This section develops a method to green monetary policy operations. Before doing so, we examine the conditions that need to be satisfied to ensure an effective conduct of monetary policy.

\subsection{Conditions}

The Treaty on the Functioning of the European Union is clear on the conditions for monetary policy. The Eurosystem (consisting of the ECB and the participating national central banks) shall support the general economic policies of the EU, without prejudice to price stability (see Article 127(1) TFEU). Maintaining price stability is thus the priority, and should not be overridden by the possible greening of monetary policy operations. So, a monetary policy decision and its implementation should not be affected by low-carbon considerations in relation to assets and collateral. The ECB should make an independent assessment of whether the 'without prejudice' clause can be fulfilled, because the ECB is not allowed to take instructions from EU institutions in the exercise of its monetary policy mandate (Article 130 TFEU).

Monetary policy can be seen as a two-stage process. In the first stage, the relevant policy decision is taken. Taking a broad definition of central bank operations, policy decisions refer to monetary policy (for example, the interest rate), to reserve management (for example, the asset and currency composition of official reserves) and to large-value payment systems (for example, safe collateral for real-time gross settlement). In the second stage, policy decisions are implemented through market transactions following operational procedures. A common element of these procedures is that central banks aim to remain market neutral wherever possible in order not to impair the functioning of the markets and price formation (Bindseil et al., 2017; Cœuré, 2018). Article $127(1)$ of the TFEU specifies that 'The ECB shall act in accordance with the principle of an open market economy with free competition, favouring an efficient allocation of resources'. 
The market pricing mechanism is thus the primary mechanism for resource allocation and is the main basis of the concept of market neutrality. Hong et al. (2019) investigated whether stock markets efficiently price risks caused by climate change. Their findings provide evidence that the price formation of carbon risk does not work smoothly. Another problem is that the asset allocation is not neutral with respect to carbon emissions. Matikainen et al. (2017), for example, find an overallocation towards high-carbon companies in the ECB's asset portfolio resulting in $57 \%$ higher carbon emissions. This paper aims to address this carbon bias.

\subsubsection{Eligibility criteria}

As part of their operational procedures, central banks determine the criteria or requirements for assets and collateral to be eligible for use in monetary policy operations. These eligibility criteria are important for the market because eligible securities become more liquid due to their possible use by banks in their operations with their central bank (see Nyborg, 2017, for an overview). The increased liquidity service translates into a higher security price and lower yield (Nagel, 2016). The cost of capital thus decreases for the issuer of the security. The same mechanism is at work for haircuts on collateral. ${ }^{1}$ A lower haircut increases the liquidity of the security and reduces the cost of capital for its issuer (Ashcraft et al., 2011).

The greening of monetary policy operations involves steering the eligibility criteria towards low-carbon assets. The intended effect is that the cost of capital for low-carbon companies reduces relative to highcarbon companies. Figure 1 shows major differences in terms of the carbon intensity of business sectors in the euro area.

In terms of central banks' ability to conduct monetary policy, we derive three conditions to avoid disruption to the monetary transmission mechanism. The first is to avoid major adjustments in the asset mix (i.e. the mix of government bonds, agency bonds, bank bonds, corporate bonds and bank loans), currency denomination and maturity, which are chosen to smooth the conduct of monetary policy and the management of reserves. Term spreads, and thereby the shape of the yield curve, will, for example, be affected when maturities are varied (Aksoy \& Basso, 2014).

\section{Carbon Intensity (CO2 Emissions in Mt / Sales in € millions)}

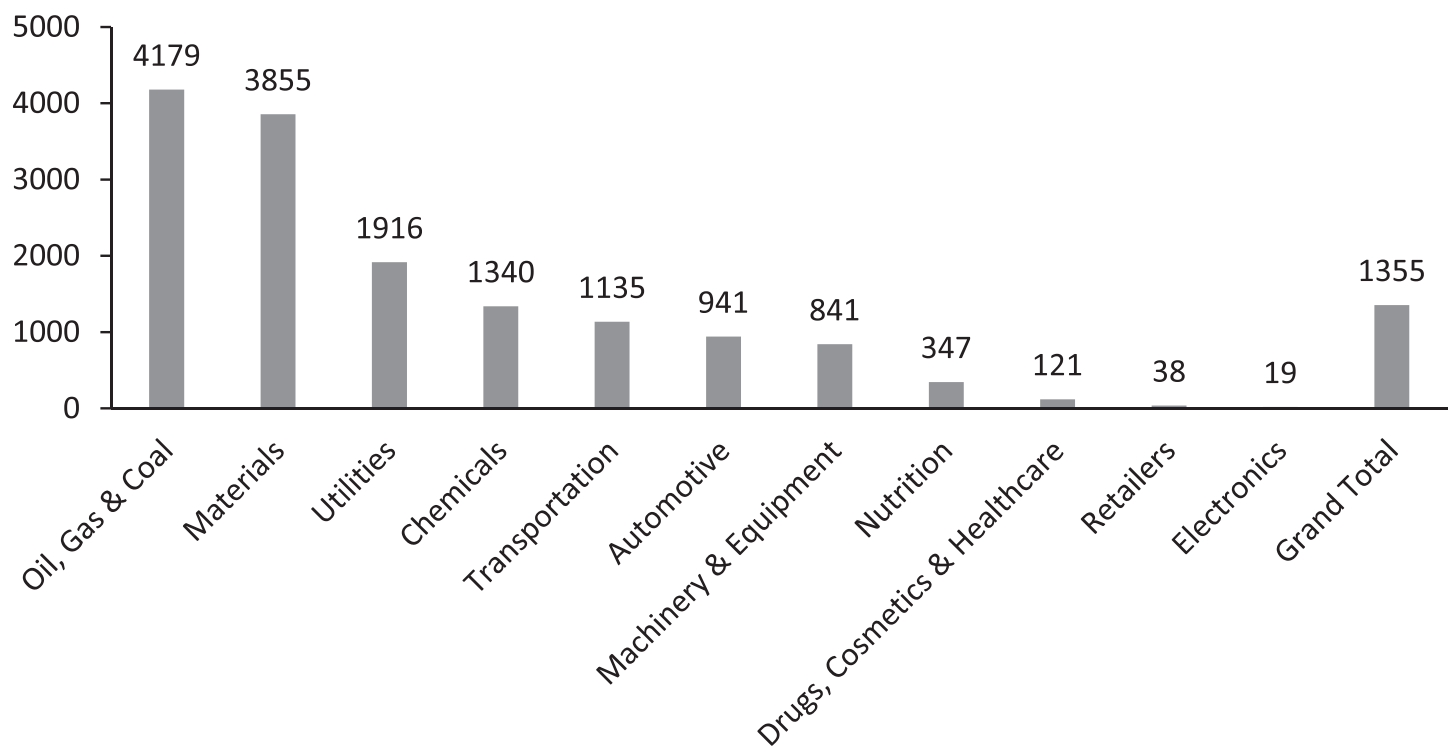

Figure 1. Average carbon intensity by industry.

Note: The graph depicts the average carbon intensity of sectors, measured as average of emissions in metric ton $\mathrm{CO} 2$ divided by sales in millions euro. Scope 1,2 and 3 emissions are included for the 60 largest corporates in the euro area. Table A1 provides a detailed breakdown.

Source: Author calculations based on ASSET4 ESG Scores in Datastream and company reports. 
The second is to keep the list of eligible assets within each asset class as broad as possible. A broad asset and collateral base contributes to minimizing the impact on the functioning of markets and price formation (Bindseil et al., 2017). It is thus very important not to 'target' particular assets (for example, only green bonds) or even asset prices of low-carbon sectors. That would impair the price stability objective of monetary policy and might erode support for central bank independence (Mishkin, 2001).

The third is to implement a possible low-carbon bias in steps, so central banks can learn about the possible impact of adjusted criteria on monetary policy transmission. A gradual implementation allows for the carbon criteria to be optimized (see Section 2.2) and the impact on the monetary transmission mechanism to be analysed. A gradual approach also allows for a smooth rebalancing of the current portfolio, which reduces the need to sell parts of high-carbon (and medium-carbon) holdings.

As maturities remain more or less the same, the possible transmission consequences are cross-sectional. Low-carbon companies face a lower cost of capital, while high-carbon companies face a higher cost of capital. The resulting transition dynamics in the economy might have an impact on the transmission channel. Central banks should analyse these dynamics and assess how monetary policy transmission might change.

\subsection{Data and methodology}

The EU's general economic policies aim at achieving a transition to a low-carbon economy with a 50\% carbon emission reductions target by 2030 compared with 1990 levels (European Commission, 2019). We take this general objective of EU climate policies as a guide for the methodology to green monetary policy operations.

\subsubsection{Indicator}

We use carbon emissions as shorthand for all greenhouse gas (GHG) emissions, which include carbon dioxide $\left(\mathrm{CO}_{2}\right)$, methane $\left(\mathrm{CH}_{4}\right)$ and nitrous oxide $\left(\mathrm{N}_{2} \mathrm{O}\right)$. Carbon emissions are the most widely used metric on the environmental side. The Greenhouse Gas Protocol (WRI, 2015) distinguishes between direct emissions from sources that are owned or controlled by the reporting entity and indirect emissions that are a consequence of the activities of the reporting entity, but occur at sources owned or controlled by another entity. The GHG Protocol further categorizes these direct and indirect greenhouse gas (GHG) emissions into three scopes:

- Scope 1: All direct GHG emissions of an entity.

- Scope 2: Indirect GHG emissions from consumption of purchased electricity, heat or steam.

- Scope 3: Other indirect emissions: the full corporate value chain emissions from the products an entity buys, manufactures and sells (e.g. for a car manufacturer, this represents the emissions of the cars in use).

Taking all three scopes into account means that, not only do the emissions of a company across its value chain matter, the emissions of products and services that it produces for its customers are also relevant. Another relevant issue is whether companies are in transition to applying low-carbon technologies and creating low-carbon products and services, or are preparing for that transition (Schoenmaker \& Schramade, 2019). So, it is important not only to assess current carbon emissions but also expected future emissions using scenarios (TCFD, 2017). This forward-looking perspective incentivises companies to switch investments from current high-carbon into new low-carbon technologies and products.

The carbon intensity of companies can be measured as follows:

$$
C l_{i, t}=\frac{\text { Emissions }_{i, t+k}}{\text { Sales }_{i, t+k}}
$$

where $C l_{i, t}$ represents the carbon intensity of company $i$ at time $t$ in years. The carbon intensity is calculated as a company's scope 1 to 3 emissions divided by its sales at time $t+k$. Emissions are measured with some delay, so $k$ would typically be -1 . We propose to start with historical carbon emissions $(k=-1)$. When companies have more experience of reporting expected future carbon emissions following the TCFD principles for scenarios and auditors are able to provide assurance on these reported emissions, the indicator could be based on a mix of current and future emissions. 
While the carbon intensity of non-financial companies issuing corporate bonds can be assessed directly, it is more difficult for synthetic or financial institution securities. The look-through approach can be applied, whereby the underlying beneficiary instead of the intermediary is assessed (Gorton \& Souleles, 2007). In the case of asset-backed securities, the carbon intensity of the assets in the vehicle (e.g. real estate underlying mortgage-backed securities) can be measured. In the case of bank loans, the carbon intensity of the borrower can be assessed. In the more general case of bank bonds, the carbon intensity of a bank's total loan portfolio should be evaluated.

Banks lend not only to companies, but also to households mostly in the form of mortgages. The carbon intensity of a mortgage can be measured by the energy label of the house, which, in the EU, ranges from A (most efficient) to $\mathrm{G}$ (least efficient). In the $\mathrm{EU}$, all properties when sold have to obtain an energy performance certificate that places the property on an A-G scale.

\subsubsection{Data}

Data on companies' carbon emissions is available at ASSET4 ESG Scores in Datastream (Thomson Reuters) and the Carbon Disclosure Project (CDP). When external emissions data or energy efficiency labels are not available, banks must provide an internal rating when supplying assets or collateral to the central bank. This is in line with the general ECB asset and collateral framework, under which banks are allowed to provide an internal credit rating for assets for which no external credit ratings exist $(E C B, 2015)$.

We take emissions and sales data from ASSET4 Datastream for the largest 60 companies in the Euro area. As we are interested in corporate bonds, we selected the largest companies by long-term debt. The Appendix provides a list of companies and their carbon intensity (Table A1). Figure 1 summarizes the average carbon intensity for each sector. As expected, the oil, gas and coal sector has the highest carbon intensity at 4179 (measured as metric tonnes of carbon emissions divided by sales in millions of euros) followed by the materials sector (metal producers and construction) at 3855, utilities at 1916, chemicals at 1340, transportation (airlines) at 1135 and automotive (carmakers) at 941, while the weighted average is 1355 (see the Appendix for details).

\subsubsection{Methodology}

Which perspective should central banks adopt in their approach towards carbon emissions? Climate change poses a physical risk (in case of insufficient mitigation) and a transition risk (in case of sudden implementation of carbon policies). It is often argued that central banks should manage the carbon risk in their operations, just like managing credit and market risks. While the risk perspective is relevant for the financial stability side (Carney, 2015), both the risk and opportunity perspective are relevant for monetary policy. Monetary policy operations should avoid the risks of a high carbon bias and grasp the opportunity to support the shift to a low-carbon economy.

Amel-Zadeh and Serafeim (2018) distinguish several methods for considering environmental, social and governance (ESG) issues:

(1) Exclusionary/negative screening: a method of deliberately not investing in companies that do not meet specific ESG criteria.

(2) Best in class: an approach to sustainable investing that focuses on investing in companies that perform better on ESG issues than their peers do.

(3) Portfolio tilt: the use of certain investment strategies or products to change specific aggregate ESG characteristics of a fund or investment portfolio to a desired level.

(4) Active ownership: use of shareholder power to engage with companies to improve their ESG performance.

(5) Thematic investing: focusing on those parts of the universe that benefit from and provide solutions for certain ESG trends.

(6) Impact investing: an approach to investing that deliberately aims for both financial and societal value creation, as well as the measurement of societal value creation.

(7) Full ESG integration: the explicit integration of E, S and G issues into the valuation and selection of securities. 
The advantages and disadvantages of the different methods can be judged on (i) political acceptability; (ii) objective and expected impact; and (iii) compatibility with the central bank's mandate. On the first criterion, Smits (1997) argues that a general approach avoids politically sensitive decisions on specific sectors and companies. While the first three methods are generally applicable, the last four methods are not. They require specific choices, valuations or actions. Full ESG integration, for example, would require that central bank officials investigate individual companies and come to a judgement on their ESG performance and transition preparedness (Schoenmaker \& Schramade, 2019).

Amel-Zadeh and Serafeim (2018) report that negative screening is the most used method among investment professionals. At the same time, however, investment professionals perceive negative screening as the least useful method, because it aims only to avoid the worst performers from a risk perspective. So, negative screening is less able to achieve the objective of addressing the carbon bias and achieving the desired impact.

The best in class and portfolio tilt methods are risk and opportunity driven. These methods can be used to select relatively low-carbon assets or to tilt the asset and collateral portfolio towards less carbon-intensive assets. This in turn reduces the exposure to high-carbon assets, meeting the objective. These methods target companies only on their contribution to carbon emissions aligned with the EU general policy of reducing carbon emissions.

The best in class method selects the $\mathrm{X} \%$ of best performers in a sector, that is, the $\mathrm{X} \%$ of companies with the lowest carbon emissions in this sector. To keep a broad asset and collateral base for central bank operations, $\mathrm{X}$ should be set relatively high, say $50-60 \%$. Even with these high numbers, $40-50 \%$ of the companies in the market is excluded. By contrast, a tilting approach increases the share of low-carbon companies at the expense of the share of high-carbon companies. A tilting approach is less distorting in the monetary transmission, as no assets are excluded (only the weights in the portfolio are adjusted). The central bank can thus maintain a broad asset and collateral base in line with its monetary policy mandate.

\subsubsection{Tilting towards low carbon}

To minimize distortions in the asset and collateral base, we propose a tilting approach for a central bank's direct asset holdings (e.g. related to official reserves or asset purchases under quantitative easing) and collateral holdings. A straightforward application is to relate the relative share of a company's securities inversely to its carbon intensity. In a tilting approach, a central bank overweights low-carbon companies and underweights highcarbon companies in its portfolio:

$$
S_{i, t}^{c b}=\left(1+p t_{i, t}\right) S_{i, t}^{m}
$$

where $S_{i, t}^{m}$ represents the share of asset $i$ in the available market portfolio $m ; S_{i, t}^{c b}$ the share of asset $i$ in the central bank portfolio $c b$, and $p t_{i, t}$ the tilting factor of asset $i$. Note that $\sum_{i}^{n} p t_{i, t}=0$. Combining Equations (1) and (2), the reduction $R_{t}^{c b}$ in carbon intensity of the central bank portfolio is as follows:

$$
R_{t}^{c b}=\frac{\sum_{1}^{n}-p t_{i, t} \cdot S_{i, t}^{m} \cdot C l_{i, t}}{\sum_{1}^{n} S_{i, t}^{m} \cdot C l_{i, t}}
$$

The aim of a haircut is to reduce the market value of an asset for collateral purposes, as this market value can fluctuate. An additional haircut can be directly related to carbon intensity, just like credit risk. A central bank then applies an additional haircut for medium and high-carbon assets. Following Nyborg (2017), the impact of an additional haircut on asset values works as follows:

$$
V_{i, t}^{c}=\left(1-\left(1+a_{i, t}\right) h_{i, t}\right) V_{i, t}^{m}
$$

where $V_{i, t}^{c}$ represents the collateral value of asset $i ; V_{i, t}^{m}$ the market value of asset $i, h_{i, t}$ the standard valuation haircut of asset $i$, and $a_{i, t}$ the additional haircut of asset $i$. Table A2 in the Appendix provides an overview of the standard valuation haircuts used by the ECB (2015). The collateral framework aims to reflect market realities and to ensure a level playing field across different jurisdictions and counterparties. Its main focus is on protecting against counterparty risk. While haircuts are often presented in absolute terms (e.g. $1 \%$ or $2 \%$ ), we propose a multiplier approach for the additional haircut to ensure proportionality. An additional haircut of, for example, 
Table 1. Carbon factors in the asset and collateral framework.

\begin{tabular}{lcclc}
\hline & & & \multicolumn{2}{c}{ Carbon intensity } \\
\cline { 2 - 4 } Carbon category & Portfolio tilt $(p t)$ & Additional haircut $(a)$ & Companies (tertile) & Houses (eco-label) \\
\hline Low & 1.00 & 0 & Bottom & A, B \\
Medium & -0.33 & 0.1 & Middle & C, D, E \\
High & -0.67 & 0.2 & Top & F, G \\
\hline
\end{tabular}

Notes: Assets are divided over three carbon categories according to their carbon intensity. The tilting factor ( $p t$ ) is applicable to a central bank's asset purchases and the additional haircut $(a)$ to its collateral.

$2 \%$ is very punitive for short-dated high-quality liquid assets with a valuation haircut of $0.5 \%$ or $1 \%$ and not very effective for longer-dated illiquid assets of a lower quality with valuation haircuts of up to $44 \%$. The aim is to tilt towards low-carbon assets within each category.

Table 1 presents a simple structure for carbon factors in the ECB's asset and collateral framework. Three carbon categories $C^{j}$ are introduced: low $\left(C^{\text {low }}=1\right)$, medium $\left(C^{\text {medium }}=2\right)$ and high $\left(C^{\text {high }}=3\right)$. Companies $i=1, . ., n$ are divided in tertiles according to increasing carbon intensity $C l_{i, t}$ : the bottom tertile is $\left[1, \frac{1}{3} n\right]$, the middle tertile is $\left(\frac{1}{3} n, \frac{2}{3} n\right]$ and the top tertile $\left(\frac{2}{3} n, n\right]$. Houses (used as collateral in mortgages) are divided according to their energy efficiency label, ranging from A to G. For bonds of financials (e.g. (un)covered bank bonds) or special purpose vehicles (e.g. asset-backed securities), a weighted average of the carbon category of the underlying assets with weight $w_{i}$ is taken, whereby a strict definition is applied: $C^{j} \geq C^{j, \text { avg }}=\sum_{i} w_{i} C_{i}^{j}$.

Moving to the carbon factors, the minimal value of the tilting factor $p t_{i}$ is -1 , as asset shares cannot become negative. The tilting factor range is $[-1, j-1)$ in a structure with $j$ categories. The maximum tilting factor in our setting with 3 carbon categories approaches 2 . To avoid major distortions, we suggest a medium tilting factor of +1 for low-carbon assets, which is divided as follows: one-third $(-0.33)$ for medium-carbon assets and two-third $(-0.67)$ for high-carbon assets. The additional haircut for collateral is initially set at 0.1 for medium-carbon assets and 0.2 for high-carbon assets in Table 1. The Eurosystem can introduce the tilting factors and additional haircuts in a stepwise order until the current carbon bias of $57 \%$ is eliminated in the ECB's asset and collateral holdings. A stepwise implementation also softens the impact on the value of companies.

\section{Results and effects of greening monetary policy}

\subsection{Asset and collateral base}

We examine the effects of greening monetary policy on the assets acquired under quantitative easing (i.e. the ECB's Asset Purchases Programme or APP) and the collateral used in regular monetary policy operations. Table A3 in the Appendix provides an overview of the consolidated balance sheet of the Eurosystem, which comprises the ECB and the participating national central banks. The largest items on the Eurosystem balance sheet refer to securities holdings under the Asset Purchases Programme (€2639 billion in item 7.1) and lending to EU credit institutions as part of monetary policy operations ( $€ 619$ billion in item 5 ). The remaining items refer to gold (item 1), IMF drawing rights and other external claims (item 2), euro government securities (item 8) and other assets (item 9). The carbon factors are not relevant for these remaining items.

Table 2 breaks down the securities holdings under the APP. The first column indicates the eligible market securities, the second column the holdings under the APP and the third column the holdings as percentage of eligible market securities. Government securities ( $€ 2157$ billion) form the vast majority of these securities at more than $80 \%$. The carbon factors are only relevant for the private securities, which amount to $€ 483$ billion. These comprise covered bank bonds ( $10.3 \%$ of total securities holdings), corporate bonds (7.1\%) and other assets (1.1\%).

Table 3 provides the collateral data of the Eurosystem taken from the ECB. The first column indicates the eligible market assets, the second column the amount used as collateral and the third column the collateral holdings as percentage of eligible market assets. Table 3 shows that banks keep the most liquid and highquality assets, like government bonds, on their own balance sheet, and pledge covered bonds (€381 billion), 
Table 2. Outstanding holdings under Asset Purchases Programme, 20 December 2019.

\begin{tabular}{|c|c|c|c|c|}
\hline Securities & $\begin{array}{l}\text { 1. Eligible market securities } \\
\text { (in } € \text { billions) }\end{array}$ & $\begin{array}{l}\text { 2. Holdings (in } € \\
\text { billions) }\end{array}$ & $\begin{array}{l}\text { 3. Holdings as share of market } \\
\text { (2. as \% of 1.) }\end{array}$ & $\begin{array}{l}\text { 4. Carbon factors applicable ( } 2 \text {. } \\
\text { as } \% \text { of total) }\end{array}$ \\
\hline $\begin{array}{l}\text { Government } \\
\text { securities }\end{array}$ & 7903.5 & 2156.9 & $27.3 \%$ & n.a. \\
\hline $\begin{array}{l}\text { Covered bank } \\
\text { bonds }\end{array}$ & 1515.3 & 268.8 & $17.7 \%$ & $10.3 \%$ \\
\hline Corporate bonds & 1558.9 & 184.8 & $11.9 \%$ & $7.1 \%$ \\
\hline $\begin{array}{l}\text { Asset-backed } \\
\text { securities }\end{array}$ & 596.8 & 29.0 & $4.9 \%$ & $1.1 \%$ \\
\hline Total & $11,574.5$ & 2639.4 & $22.8 \%$ & $18.5 \%$ \\
\hline
\end{tabular}

Source: ECB (EURO outright operations). Note: The second column presents marketable securities that are eligible under the APP. The third column presents the holdings under the APP. The fourth column presents APP holdings as share of eligible market securities. The fifth column indicates whether the carbon factor would be applicable to the respective collateral category and measures the percentage of total holdings.

asset-backed securities ( $€ 359$ billion) and bank loans ( $€ 380$ billion) as collateral at the Eurosystem. ${ }^{2}$ The carbon factors can be applied to slightly over $80 \%$ of the Eurosystem's collateral holdings (see last column of Table 3 ). This indicates that the tilting approach has a bigger impact on collateral (81.0\%) than on asset purchases (18.5\%).

\subsection{Numerical examples}

The way central banks can put the tilting method into operation is illustrated with numerical examples. We take corporate bonds, unsecured and covered bank bonds, which are large asset classes in the ECB's asset and collateral framework alongside government bonds. Starting with corporate bonds, we examine the impact of the tilting factor on the carbon footprint of a portfolio with corporate bonds. For the calibration of the corporate bond portfolio, we construct the market portfolio of eligible corporate bonds by taking the corporate bonds of the 60 largest companies in the euro area, which means that $n=60$, measured by long-term debt $D_{i, t}$ (see the Appendix). The value weighted share of company $i$ in the market portfolio is then:

$$
S_{i, t}^{m}=\frac{D_{i, t}}{\sum_{i}^{n} D_{i, t}} .
$$

Table 3. Collateral data of the Eurosystem, 20 December 2019.

\begin{tabular}{|c|c|c|c|c|}
\hline Collateral categories & $\begin{array}{l}\text { 1. Eligible market assets } \\
\text { (in } € \text { billions) }\end{array}$ & $\begin{array}{c}\text { 2. Use of collateral (in } \\
€ \text { billions) }\end{array}$ & $\begin{array}{l}\text { 3. Collateral as share of } \\
\text { market }(2 . \text { as } \% \text { of } 1 .)\end{array}$ & $\begin{array}{l}\text { 4. Carbon factors applicable } \\
\text { (2. as \% of total) }\end{array}$ \\
\hline $\begin{array}{l}\text { Central government } \\
\text { securities }\end{array}$ & 7432.8 & 225.2 & $3.0 \%$ & n.a. \\
\hline $\begin{array}{l}\text { Regional government } \\
\text { securities }\end{array}$ & 470.7 & 59.6 & $12.7 \%$ & n.a. \\
\hline Uncovered bank bonds & 1679.6 & 81.2 & $4.8 \%$ & $5.1 \%$ \\
\hline Covered bank bonds & 1515.3 & 380.8 & $25.1 \%$ & $23.9 \%$ \\
\hline Corporate bonds & 1558.9 & 54.2 & $3.5 \%$ & $3.4 \%$ \\
\hline Asset-backed securities & 596.8 & 359.1 & $60.2 \%$ & $22.5 \%$ \\
\hline $\begin{array}{l}\text { Other marketable } \\
\text { assets }\end{array}$ & 874.3 & 36.8 & $4.2 \%$ & $2.3 \%$ \\
\hline Bank loans & & 379.9 & & $23.8 \%$ \\
\hline Total & $14,128.4$ & 1576.8 & $8.5 \%$ & $81.0 \%$ \\
\hline \multicolumn{5}{|l|}{ Central bank operations } \\
\hline $\begin{array}{l}\text { Monetary policy } \\
\text { operations }\end{array}$ & & 619.0 & & \\
\hline Other operations & & 957.8 & & \\
\hline
\end{tabular}

Source: ECB (Eurosystem collateral data). Note: The second column presents marketable assets that are eligible as collateral. The third column presents the collateral holdings in the Eurosystem, at market values after haircuts applied (see Table A2). The fourth column presents collateral as share of eligible market assets. The fifth column indicates whether the additional carbon haircut would be applicable to the respective collateral category. The bottom rows specify for which central bank operations collateral is used. Other operations include large-value payment system operations. 
Table 4. Tilting of corporate bond portfolio.

\begin{tabular}{|c|c|c|c|c|c|c|c|c|c|}
\hline \multirow[b]{2}{*}{$\begin{array}{l}\text { Carbon } \\
\text { category }\end{array}$} & \multirow[b]{2}{*}{$\begin{array}{c}\text { Carbon } \\
\text { intensity }\end{array}$} & \multirow[b]{2}{*}{$\begin{array}{c}\text { Fraction in } \\
\text { market } \\
\text { portfolio }\end{array}$} & \multirow{2}{*}{$\begin{array}{c}\text { Carbon } \\
\text { intensity } \\
\text { market } \\
\text { portfolio }\end{array}$} & \multicolumn{3}{|c|}{ Fraction in central bank portfolio } & \multicolumn{3}{|c|}{ Carbon intensity central bank portfolio } \\
\hline & & & & $\begin{array}{l}\text { medium } \\
\text { tilting } \mathrm{pt}= \\
1\end{array}$ & $\begin{array}{l}\text { low } \\
\text { tilting pt } \\
=0.75\end{array}$ & $\begin{array}{c}\text { high } \\
\text { tilting pt } \\
=1.25\end{array}$ & $\begin{array}{c}\text { medium } \\
\text { tilting } \mathrm{pt}= \\
1\end{array}$ & $\begin{array}{c}\text { low tilting } \\
\mathrm{pt}=0.75\end{array}$ & $\begin{array}{l}\text { high } \\
\text { tilting pt } \\
=1.25 \\
\end{array}$ \\
\hline Low & 134.0 & 0.33 & 44.7 & 0.67 & 0.58 & 0.75 & 89.3 & 78.2 & 100.5 \\
\hline Medium & 751.0 & 0.33 & 250.3 & 0.22 & 0.25 & 0.19 & 166.9 & 187.8 & 146.0 \\
\hline High & 3179.5 & 0.33 & 1059.8 & 0.11 & 0.17 & 0.06 & 353.3 & 529.9 & 176.6 \\
\hline Portfolio & & 1.00 & 1354.8 & 1.00 & 1.00 & 1.00 & 609.5 & 795.8 & 423.2 \\
\hline Reduction & & & & & & & $55.0 \%$ & $41.3 \%$ & $68.8 \%$ \\
\hline
\end{tabular}

Notes: Corporate bonds are divided over three carbon categories according to their carbon intensity (measured as metric ton $\mathrm{CO}_{2}$ divided by sales in million euros; see Figure 1); the average carbon intensity for each tertile is presented. The medium tilting factor of Table 1 is applied ( $p t=1$ for the low carbon tertile) and a sensitivity analysis with low tilting ( $p t=0.75$ for the low carbon tertile) and high tilting ( $p t=1.25$ for the low carbon tertile). The carbon footprint of the central bank portfolio after tilting is reduced with 55,41 and 69 percent respectively.

Table 4 reports the results from the tilting. Applying the carbon factors of Table 1 to Equation (2), the fraction of low-carbon corporate bonds increases from 0.33 to 0.67 and the fraction of medium and high-carbon corporate bonds decreases from 0.33 to 0.22 and 0.11 respectively. A sensitivity analysis is conducted with a low set of tilting factors $(+0.75,-0.25$ and -0.50$)$ and a high set $(+1.25,-0.42$ and -0.83$)$. In the medium tilting scenario, the carbon footprint of the central bank's corporate bond portfolio is reduced by $55 \%$ to $610 \mathrm{com}$ pared to the original market portfolio at $1355\left(R_{t}^{c b}=0.55\right.$ in Equation (3)). The lopsided distribution of carbon emissions with very high carbon intensity in some sectors (i.e. the fossil fuel, materials and utilities sectors in Figure 1) explains this strong reduction of 55\%, with a medium tilting factor of +1 for low-carbon and -0.33 and -0.67 for medium and high-carbon companies. The low tilting scenario reduces emissions with $41 \%$, while the high tilting scenario reduces emissions with $69 \%$. These results indicate that medium tilting suffices to counter the current carbon bias of $57 \%$ (see Section 2).

The second numerical example concerns the unsecured bonds of two single-A rated banks. The bonds have a residual maturity of four years and a fixed coupon, which gives a valuation haircut of $11 \%$ (see Table A2). The carbon category of unsecured bank bonds is derived from the carbon factors of the underlying loan portfolio. Table 5 reports that Bank A has $40 \%$ of its loans to companies and $60 \%$ to households (in the form of mortgages) spread across the three carbon categories. The weighted average carbon factor is 2.32 , which leads to an additional haircut of 0.2 based on the carbon factors of Table 1 . The total haircut increases from $11 \%$ to $13.2 \%$, according to Equation (4). Bank B has slightly lower carbon intensity in its loan portfolio with an average carbon factor of 1.92 . The additional haircut of 0.1 increases the total haircut from $11 \%$ to $12.1 \%$.

The third numerical example concerns a covered bank bond. Again the bank is single-A rated and the bond has a remaining maturity of four years with a fixed coupon. The valuation haircut is $3 \%$. In the case of a covered bond, the average carbon factor of the underlying houses has to be calculated. The bank has a portfolio with relatively energy efficient houses: $60 \%$ with label $A$ or $B, 30 \%$ with label $C$ to $E$, and $10 \%$ with label $F$ or $G$. The

Table 5. Additional haircut for uncovered bank bonds.

\begin{tabular}{|c|c|c|c|c|c|}
\hline \multirow[b]{2}{*}{ Carbon category } & \multirow[b]{2}{*}{ Carbon factor } & \multicolumn{2}{|c|}{ Bank A } & \multicolumn{2}{|c|}{ Bank B } \\
\hline & & Companies $40 \%$ & Mortgages $60 \%$ & Companies $60 \%$ & Mortgages $40 \%$ \\
\hline Low & 1 & 0.04 & 0.12 & 0.18 & 0.16 \\
\hline Medium & 2 & 0.12 & 0.24 & 0.24 & 0.16 \\
\hline \multirow[t]{2}{*}{ High } & 3 & 0.24 & 0.24 & 0.18 & 0.08 \\
\hline & & $\overline{0.40}$ & $\overline{0.60}$ & $\overline{0.60}$ & $\overline{0.40}$ \\
\hline Average carbon factor & & 2.32 & & 1.92 & \\
\hline Valuation haircut & & $11.0 \%$ & & $11.0 \%$ & \\
\hline Additional haircut & & 0.2 & & 0.1 & \\
\hline Total haircut & & $13.2 \%$ & & $12.1 \%$ & \\
\hline Increase of total haircut & & $20 \%$ & & $10 \%$ & \\
\hline
\end{tabular}

Notes: The single A rated banks have a loan portfolio of corporate loans and mortgages. The average carbon factor is calculated as a weighted average of a bank's asset carbon factors. The valuation haircut is based on a residual maturity of 4 years and a fixed coupon (Table A2). The additional haircut (Table 1) is based on the upward rounded carbon factor. The total haircut is calculated according to Equation (4). 
average carbon factor is 1.5, which gives rise to an additional haircut of 0.1 (Table 1). The total haircut for this covered bond increases from 3\% to 3.3\%, according to Equation (4). Only when all houses have an A or B label, is there no additional haircut.

These numerical examples show a substantial reduction in the carbon footprint of the central bank portfolio in corporate and bank bonds. Nevertheless, a broad asset base is maintained, minimizing the scope for distortions in the monetary transmission mechanism.

\subsection{Discussion}

Does an allocation bias towards low-carbon assets support the transition to a low-carbon economy? In Section 2.1, we discuss that increased eligibility for low-carbon assets generates a liquidity premium that reduces the cost of capital. The cost of capital for high-carbon companies then becomes higher than that for low-carbon companies. This primary effect already gives low-carbon companies a funding advantage and thus could contribute to the transition. But the evidence is mixed. Heinkel et al. (2001) show that when more than $20 \%$ of green investors are added to the investor base, the cost of capital for green companies declines so much that polluting companies start to reform and adopt clean technologies. By contrast, Lilliestam et al. (2021) provide evidence that carbon pricing has little effect on the adoption of low-carbon technologies.

Another channel is engagement. Institutional investors and banks engage with investee and lending companies inter alia on adopting low-carbon technologies. There is evidence showing that engagement improves the sustainability outcomes (Schoenmaker \& Schramade, 2019). By increasing (decreasing) the eligibility of lowcarbon (high-carbon) assets, the ECB would further incentivise these engagement efforts on low-carbon technologies.

Van't Klooster and van Tilburg (2020) go one step further and argue that the ECB should only provide cheap refunding (in the form of green targeted long-term refinancing operations) for bank loans that are in line with the new European green taxonomy. More generally, central bank efforts to green monetary policy operations give a powerful signalling effect to other financial market participants (Braun, 2018), boosting the case for greening the financial system.

\subsection{Implementation}

The implementation of the proposed tilting approach faces several challenges. A first challenge is reliable data on carbon emissions. These data are available under the EU's Emissions Trading System (ETS). The EU ETS company database contains the verified carbon emissions for more than 1000 companies from EU countries at group level.

Another challenge is containing undesired side-effects of pushing green investment. There are risks on both sides. High carbon companies may become stranded assets that lose their value under a scenario with a high carbon tax and/or a major technological breakthrough in renewable energy production (Caldecott et al., 2014). This is the earlier mentioned transition risk. Next, low carbon companies adopt new technologies, which are subject to the standard business risk of new ventures. Moreover, certain technologies may initially be boosted by government subsidies and subsequently affected by withdrawal of these subsidies. This is the so-called policy risk.

\section{Conclusions}

Central banks have a medium to long-term perspective and are therefore mindful of the impact of climate change. They have already started to examine the impact of climate change on the stability of the financial system from a risk management perspective. On the monetary side, there is no comparable direct impact on price stability, which has a medium-term horizon. Nevertheless, the Eurosystem's legal mandate states that it 'shall support the general policies in the EU, without prejudice to price stability'. At the same time, the transition to a low-carbon economy is a cornerstone of the EU's general economic policies. 
The Eurosystem can support the EU's climate policy by greening its monetary policy operations. We develop a methodology to tilt the asset and collateral base for monetary policy operations towards low-carbon assets. A medium tilting approach can reduce carbon emissions in the central bank's corporate and bank bond portfolio by $55 \%$ offsetting the current carbon bias. This paper shows how this can be done without unduly interfering in the smooth conduct of monetary policy. A key element of a tilting approach is that the ECB remains present in the entire market for eligible assets, which guarantees that monetary policy gets in 'all of the cracks' of the economy (Stein, 2013, p. 17). Tilting only increases the share of low-carbon assets at the expense of highcarbon assets, but it does not exclude high-carbon assets.

The required political space for the ECB to adopt low-carbon criteria is already present. The European Council, the European Commission and the European Parliament are all committed to the transition to a low-carbon economy as part of the European Green Deal (European Commission, 2019).

If the Eurosystem were to pick up the challenge of greening its monetary policy operations, it would be of utmost importance to do that in full independence. The Eurosystem could adjust the eligibility criteria for assets and collateral in a general way, using a transparent and objective indicator, such as current and future carbon emissions (TCFD, 2017). It should refrain from favouring specific projects or setting sectoral targets, which is an issue for government policy. The EU and the member states can use their multilateral development bank, the European Investment Bank, and their national development banks to steer financing towards specific green projects, if they wish to do so.

Our findings are also applicable to other central banks. The exact setting of the carbon factors (in Table 1) needs to be modified and calibrated according to the specifics of a central bank's asset and collateral framework. But the tilting approach is likely to be generally applicable to correct the carbon bias in monetary policy operations throughout the world.

\section{Notes}

1. A haircut reduces the market value of an asset for collateral purposes. The aim of a haircut is to protect against credit risk, as the market value of assets can fluctuate.

2. Some asset classes are heavily used as collateral. Banks use, for example, their asset-backed securities as collateral for the ECB, up to $60 \%$ (Table 4). Also, covered bank bonds are popular as collateral ( $24 \%$ ) and in the APP ( $21 \%$ in Table 3 ). With such high initial fractions, there is less scope for tilting. So, the tilting needs to be moderated for these asset classes to say +0.30 for lowcarbon assets and -0.10 and -0.20 for medium- and high-carbon assets.

\section{Acknowledgements}

The author is grateful for feedback from three anonymous referees and audiences at the NGFS Conference 'Scaling up Green Finance: The Role of Central Banks' at the Deutsche Bundesbank, the Institut Louis Bachelier Conference 'Green Finance Research Advances' at the Banque de France, the Conference 'Dynamics of Inclusive Prosperity' at Erasmus University, a research seminar at Bruegel and a seminar at the European Central Bank. He would also like to thank Dion Bongaerts, Maria Demertzis, Frank Elderson, Gianfranco Gianfrate, Charles Goodhart, David-Jan Jansen, Clemens Kool, Andre Sapir, Willem Schramade, Marijn van der Sluis, Bert Smid, René Smits, Job Swank, Rens van Tilburg, Casper de Vries, Mark Weth, and Guntram Wolff for useful comments and Tim Kievid for excellent research assistance. The views in this paper are those of the author.

\section{Disclosure statement}

No potential conflict of interest was reported by the author(s).

\section{References}

Aksoy, Y., \& Basso, H. (2014). Liquidity, term spreads and monetary policy. Economic Journal, 124(581), 1234-1278. https://doi.org/10. 1111/ecoj.12087

Amel-Zadeh, A., \& Serafeim, G. (2018). Why and how investors use ESG information: Evidence from a global survey. Financial Analysts Journal, 74(3), 87-103. https://doi.org/10.2469/faj.v74.n3.2

Ashcraft, A., Gârleanu, N., \& Pedersen, L. (2011). Two monetary tools: Interest rates and haircuts. In: D. Acemoglu \& M. Woodford (Eds.), NBER Macroeconomics Annual 2010, 25(1), 143-180. https://doi.org/10.1086/657530 
Battiston, S., Mandel, A., Monasterolo, I., Schütze, F., \& Visentin, G. (2017). A climate stress-test of the financial system. Nature Climate Change, 7(4), 283-288. https://doi.org/10.1038/nclimate3255

Bindseil, U., Corsi, M., Sahel, B., \& Visser, A. (2017). The Eurosystem collateral framework explained (ECB Occasional Paper Series No. 189).

Braun, B. (2018). Central banking and the infrastructural power of finance: The case of ECB support for repo and securitization markets. Socio-Economic Review, 16(1), 1-24. https://doi.org/10.1093/ser/mwy012

Caldecott, B., Tilbury, J., \& Carey, C. (2014). Stranded assets and scenarios (Discussion Paper). Smith School of Enterprise and the Environment, University of Oxford.

Campiglio, E., Dafermos, Y., Monnin, P., Ryan-Collins, J., Schotten, G., \& Tanaka, M. (2018). Climate change challenges for central banks and financial regulators. Nature Climate Change, 8(6), 462-468. https://doi.org/10.1038/s41558-018-0175-0

Carney, M. (2015, September 29). Breaking the tragedy of the horizon: Climate change and financial stability. Speech at Lloyd's of London.

Cœuré, B. (2018, November 8). Monetary policy and climate change. Speech at the NGFS Conference 'Scaling up Green Finance: The Role of Central Banks' at the Deutsche Bundesbank.

Doda, B. (2016). Sector-level carbon intensity distribution (Centre for Climate Change Economics and Policy Working Paper No. 281).

European Central Bank (ECB). (2015). Guideline (EU) 2015/510 of the ECB of 19 December 2014 on the implementation of the Eurosystem monetary policy framework (ECB/2014/60). Official Journal of the European, L91/3-135.

European Commission. (2019). The European Green Deal. Communication from the Commission, COM(2019) 640 final, Brussels.

Gorton, G., \& Souleles, N. (2007). Special purpose vehicles and securitization. In M. Carey \& R. Stulz (Eds.), The risks of financial institutions (pp. 549-602). University of Chicago Press.

Heinkel, R., Kraus, A., \& Zechner, J. (2001). The effect of green investment on corporate behavior. Journal of Financial and Quantitative Analysis, 36(4), 431-449. https://doi.org/10.2307/2676219

Hong, H., Li, F., \& Xu, J. (2019). Climate risks and market efficiency. Journal of Econometrics, 208(1), 265-281. https://doi.org/10.1016/j. jeconom.2018.09.015

Lilliestam, J., Patt, A., \& Bersalli, G. (2021). The effect of carbon pricing on technological change for full energy decarbonization: A review of empirical ex-post evidence. Wiley Interdisciplinary Reviews: Climate Change, 12(1), e681. https://doi.org/10.1002/wcc.681

Matikainen, S., Campiglio, E., \& Zenghelis, D. (2017). The climate impact of quantitative easing (Policy Paper). Grantham Research Institute on Climate Change and the Environment.

Mishkin, F. (2001). The transmission mechanism and the role of asset prices in monetary policy (NBER Working Paper No. 8617).

Nagel, S. (2016). The liquidity premium of near-money assets. Quarterly Journal of Economics, 131(4), 1927-1971. https://doi.org/10. 1093/qje/qjw028

Nyborg, K. (2017). Collateral frameworks: The open secret of central banks. Cambridge University Press.

Reinders, H. J., Schoenmaker, D., \& van Dijk, M. (2020). A finance approach to climate stress testing (CEPR Discussion Paper DP14609). Schoenmaker, D., \& Schramade, W. (2019). Principles of sustainable finance. Oxford University Press.

Smits, R. (1997). The European central bank: Institutional aspects. Kluwer Law International.

Stein, J. (2013). Overheating in credit markets: Origins, measurement, and policy responses, speech delivered at the research symposium sponsored by the Federal Reserve Bank of St. Louis, Restoring household financial stability after the great recession: Why household balance sheets matter.

Stern, N. (2008). The economics of climate change. American Economic Review, 98(2), 1-37. https://doi.org/10.1257/aer.98.2.1

Stiglitz Report. (2009). Report by the commission on the measurement of economic performance and social progress.

Task Force on Climate-related Financial Disclosures (TCFD). (2017). Recommendations of the task force on climate-related financial disclosures: Final report (Bloomberg Report). Financial Stability Board.

Van't Klooster, J., \& van Tilburg, R. (2020). Targeting a sustainable recovery with Green TLTROs (Working Paper). Positive Money Europe and Sustainable Finance Lab.

World Resources Institute (WRI). (2015). Greenhouse gas protocol. Washington DC: WRI. 